\title{
Activation of the Medial Septum Reverses Age-Related Hippocampal Encoding Deficits: A Place Field Analysis
}

\author{
Simona Sava ${ }^{1,2}$ and Etan J. Markus ${ }^{1}$ \\ ${ }^{1}$ Behavioral Neuroscience Division, Department of Psychology, University of Connecticut, Storrs, Connecticut 06269, and ${ }^{2}$ Department of Psychiatry, \\ Harvard Medical School and Brain Imaging Center, McLean Hospital, Belmont, Massachusetts 02478
}

When a rat runs through a familiar environment, the hippocampus retrieves a previously stored spatial representation of the environment. When the environment is modified a new representation is seen, presumably corresponding to the hippocampus encoding the new information. The medial septum is hypothesized to modulate whether the hippocampus engages in retrieval or encoding. The cholinergic agonist carbachol was infused into the medial septum, and hippocampal CA1 place cells were recorded in freely moving rats. In a familiar environment, septal activation impaired the retrieval of a previously stored hippocampal place cell representation regardless of age. When the environment was changed, medial septal activation impaired the encoding process in young, but facilitated the encoding of the new information in aged rats. Moreover, the improved encoding was evident during a subsequent exposure to the modified environment $24 \mathrm{~h}$ later. The findings support the role the septum plays in modulating hippocampal retrieval/encoding states. Furthermore, our data indicate a mechanism of age-related cognitive impairment.

Key words: aging; cholinergic; carbachol; memory; remapping; place field

\section{Introduction}

Age-related memory decline is associated with hippocampal dysfunction (Rapp and Amaral, 1991; Jenkins et al., 2000; Zhang et al., 2007). Hippocampal pyramidal cells ("place cells") fire strongly when the rat is in a particular location in the environment ("place field"). Place fields typically remain in the same location across repeated exposures to an environment (O'Keefe and Nadel, 1978; Thompson and Best, 1990). This "map" of the environment can remain constant despite the removal (O'Keefe and Speakman, 1987; Markus et al., 1994) or exchange of stimuli (Tabuchi et al., 2003), suggesting that a stored representation of the environment is repeatedly evoked despite slight changes in the environment (McNaughton and Morris, 1987). When the environment or task requirements are altered, place cells can "remap" (i.e., change their spatial tuning or stop firing). Unlike the recall of a previously stored representation, remapping indicates encoding or establishing a new representation of the environment (Frank et al., 2006).

In aged rats, place fields are as stable as those observed in young animals within a given recording session in a familiar environment (Markus et al., 1994; Oler and Markus, 2000; Wilson et al., 2004, 2005). However, under conditions that normally induce remapping in young rats, less remapping is found in aged

Received June 8, 2007; revised Dec. 12, 2007; accepted Dec. 31, 2007

This work was supported by University of Connecticut FRS445142 and National Institutes of Health Grant R29A613941-01A1 (E.J.M.). We thank Dr. Monty Escabi for his help with the EEG data analysis, Gregory Peters and Mark Brandon for assistance conducting the experiments, Dr. James Chrobak for useful comments on the design of the study, and Dr. Jamie Bunce for helping with the design of the study and the revision of this manuscript.

Correspondence should be addressed to Dr. Etan J. Markus, Behavioral Neuroscience Division, Department of Psychology, University of Connecticut, U-1020, Storrs, CT 06269. E-mail: etan.markus@uconn.edu.

D01:10.1523/JNEUROSCI.4629-07.2008

Copyright $\odot 2008$ Society for Neuroscience $\quad$ 0270-6474/08/281841-13\$15.00/0 animals (Oler and Markus, 2000; Wilson et al., 2004). This rigidity of the hippocampal representation may underlie the agerelated impairments in spatial processing and episodic memory formation (Wilson et al., 2004).

Although major changes in the environment can induce a switch from retrieval of a representation to encoding a new representation, the mechanisms underlying the transition are unknown. The current study examined the hypothesis that the medial septum (MS) modulates the transition between retrieval and encoding states by regulation of hippocampal theta $(4-12 \mathrm{~Hz}$ field oscillation). Theta has been related to exploration (Buzsaki, 2002) and increased neuronal plasticity (Judge and Hasselmo, 2004), and may act to synchronize activity across different neural regions during the encoding phase of learning (Hasselmo et al., 2002).

Inactivation of the MS decreases hippocampal theta and spatial task performance (Givens and Olton, 1990; Markowska et al., 1995). Similarly, the cholinergic modulation of the hippocampus is reduced during aging in rats (Gill and Gallagher, 1998), as well as humans (Bartus et al., 1982). Conversely, intraseptal cholinergic drugs increase hippocampal theta power (Lee et al., 1994; Givens and Olton, 1995; Markowska et al., 1995), and can promote memory performance in scopolamine-treated or aged memory-impaired rats (Givens and Olton, 1995; Markowska et al., 1995; Sabolek et al., 2004a), but not in young rats (Markowska et al., 1995; Frick et al., 1996; Bunce et al., 2003).

The present study examined whether increased MS activation (by intraseptal carbachol, a cholinergic agonist) would promote remapping, indicating the encoding or establishment of a new representation of the environment within the hippocampus. Our results indicate that in a familiar environment, in which the hippocampus normally retrieves a stored representation, MS activa- 
tion interfered with the recall process. In a novel configuration, in which aged animals normally show reduced encoding, MS activation enhanced encoding.

\section{Materials and Methods \\ Subjects}

The subjects were seven young adult (6-10 months old) and eight aged (22-23 months old) Fisher-344 male rats. Rats were single housed in transparent plastic tubs, in a room with a $12 \mathrm{~h}$ light/dark cycle. All experimental procedures were conducted in accordance with the guidelines of the University of Connecticut Animal Care Committee.

Training procedure

Adaptation. All animals were food deprived to $85-90 \%$ of their ad libitum weight. Before starting the training for the electrophysiological recordings, the rats were trained to traverse runways for chocolate sprinkle reward. The majority of rats were also trained to perform a mixed working and reference memory task on a radial arm maze for 2 weeks. Animals showing robust running were subsequently trained on the alternation task.

Alternation task. After finishing adaptation training, rats were placed on an automated runway and trained to alternate for food reinforcement (Noyes Precision Pellets, New Brunswick, NJ) between the ends of two arms of a sevenposition maze (Fig. $1 \mathrm{~A}$, black arms). The rats were trained for $30 \mathrm{~min}$ a day until they reached a criterion of 80 trials (i.e., traversing the runway in one direction) per day on at least 2 consecutive days of training. The maze was located in the recording room, where several large stable extramaze cues were available (door, chairs, lamp, etc.)

\section{Surgery}

After reaching criterion, rats were anesthetized with a ketamine mixture (i.m.; ketamine, 12.5 $\mathrm{mg} / \mathrm{ml}$; acepromazine, $0.25 \mathrm{mg} / \mathrm{ml}$; xylazine, $1.25 \mathrm{mg} / \mathrm{ml}$ ). Each rat received initial doses of $49.6 \mathrm{mg} / \mathrm{kg}$ ketamine, 0.4 $\mathrm{mg} / \mathrm{kg}$ acepromazine, and $5.08 \mathrm{mg} / \mathrm{kg}$ xylazine, and additional boosters as needed (total dosage given did not exceed double the initial dose). They were implanted with a cannula aimed at the MS $(0.5 \mathrm{~mm}$ anterior, $0 \mathrm{~mm}$ lateral, $4.5 \mathrm{~mm}$ ventral from bregma), as well as a microdrive for EEG and single-unit recordings aimed at the dorsal hippocampus (3.2 $\mathrm{mm}$ posterior, $\pm 2.2 \mathrm{~mm}$ lateral, $1 \mathrm{~mm}$ ventral from bregma). The microdrive was composed of one $60 \mu \mathrm{m}$ tungsten wire for EEG recordings and eight movable tetrodes (four in each hemisphere) for hippocampal unit recordings (Wilson and McNaughton, 1993). Each tetrode comprised four polyamide-insulated $14 \mu \mathrm{m}$ nichrome wires $(\mathrm{H}$. P. Ried, Palm Coast, FL) that were twisted together. Rats received $0.1 \mathrm{mg} / \mathrm{kg}$ meloxicam (Metacam; Boehringer Ingelheim, St. Joseph, MO) per os for $4-5 \mathrm{~d}$ after surgery.

\section{Recording procedure}

After recovery from surgery, animals were retrained on the alternation task. The electrodes were slowly lowered into the CA1 region of the hippocampus, until single units could be isolated. Single-unit data were collected when the animal sat quietly in its home cage outside the maze room, and also on the maze, when the rat was performing the alternation task, in either a familiar or novel maze configuration.

Familiar configuration. Recordings were performed in four stages: (1) Holder preinfusion data were recorded while the rat was sitting quietly in a home cage outside of the recording room. (2) Maze preinfusion data were collected for 9 min while the rat was running on the maze. The recording was stopped and the rat was returned to its home cage, where a sham or drug infusion (saline or carbachol) was performed. During the break, the maze was carefully cleaned with $30 \%$ alcohol to remove odor cues. (3) Maze postinfusion data were collected while the rat ran the familiar alternation task for $9 \mathrm{~min}$. (4) Holder postinfusion data were collected while the rat sat in the home cage for $10 \mathrm{~min}$ (Fig. 1A).

Novel configuration. For each rat, up to five novel configuration recordings were conducted by moving one of the maze arms to a new location (one of the gray arm positions in Fig. 2A). The same recording apparatus and room were used for the familiar and novel configuration recordings. Recordings in a novel configuration were performed as follows. (1) Holder preinfusion data were recorded while the rat was sitting quietly in its home cage outside of the recording room. (2) Maze preinfusion data were collected while the rat ran 20 trials on familiar configuration on the maze (Fig. $2 \mathrm{~A}, \mathrm{~F}$ and $\mathrm{F}^{*}$ arms). The recording was stopped and an infusion was performed. The maze was cleaned with $30 \%$ alcohol. (3) Maze postinfusion data were collected while the rat ran a novel configuration for $12 \mathrm{~min}$. (4) Holder postinfusion data were collected while the rat sat in the home cage for $10 \mathrm{~min}$. The procedure was repeated $24 \mathrm{~h}$ later (in the same preinfusion and postinfusion arm configurations), at which time a sham infusion was performed.

The sequence was as follows. The configuration that the rat had been exposed to during training was 1-6 (the first familiar configuration), and the first two novel configurations were obtained by rotating the $\mathrm{F}^{*}$ arm by 


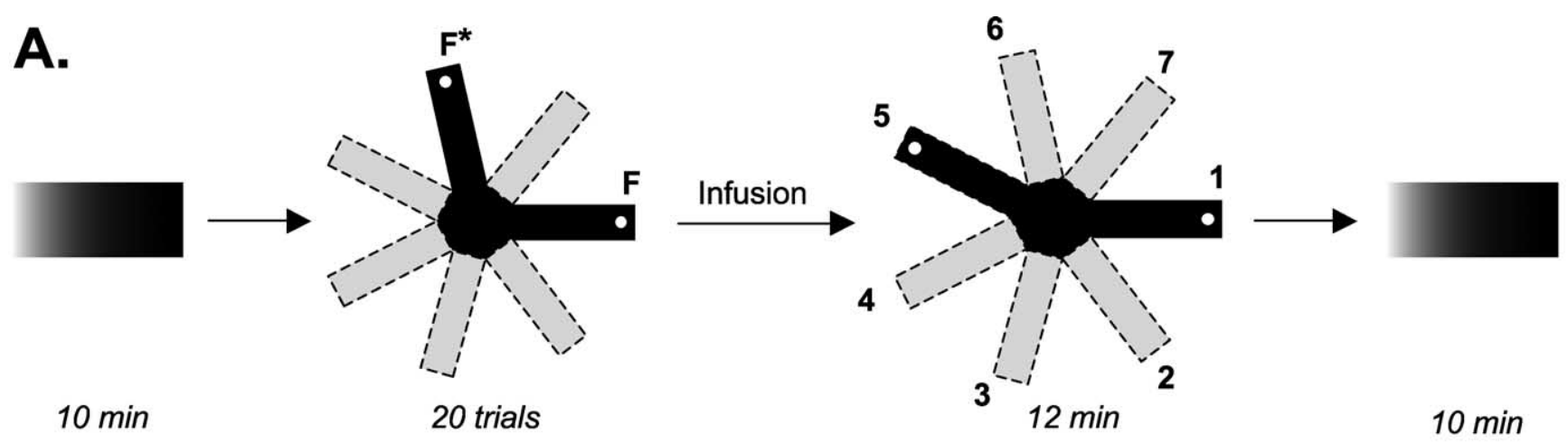

\section{B. \\ Familiar Configuration}

\section{Novel Configuration}
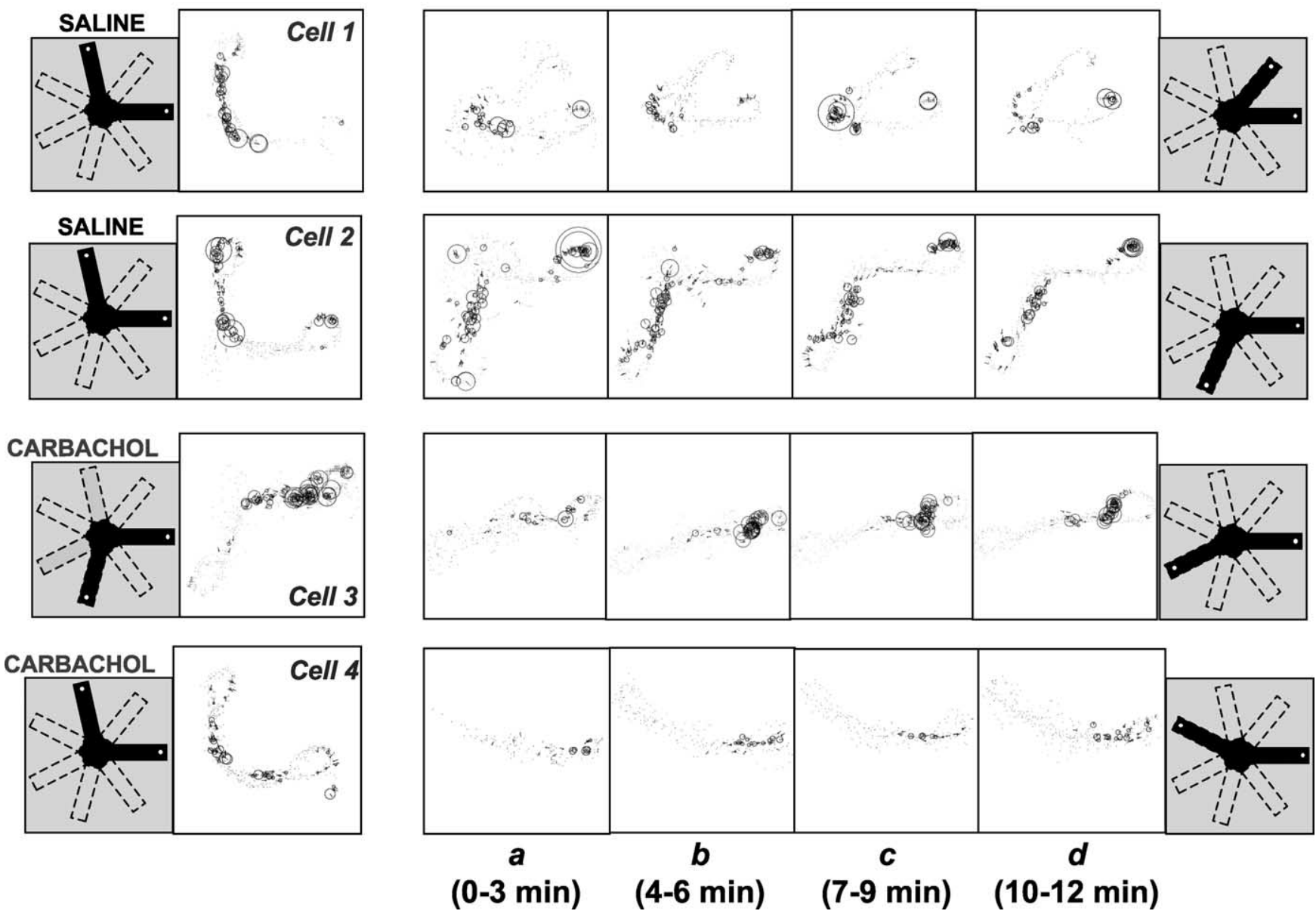

Figure 2. Schematic of the maze configuration and examples of place-related activity of neurons recorded in the novel configuration. $A$, The novel configuration was obtained by rotating one of the arms of the maze $\left(F^{*}\right)$ to a novel location for the postinfusion recording; in this example, rotating the arm from familiar position 6 to position 5 . The preinfusion recording ended after the rat completed 20 trials on the maze. The postinfusion recording lasted for $12 \mathrm{~min}$. B, Examples of spatial specific firing of four neurons recorded from young rats. The firing in the preinfusion recording is shown on the left; the postinfusion recording in shown on the right, and is broken down in $3 \mathrm{~min}$ intervals. The graphic representation of the firing is the same as in Figure 1.

$51.4^{\circ}$ to one of its adjacent positions (i.e., 5 or 7 ). The next novel configuration of the maze the rats experienced was $1-3\left(154.2^{\circ}\right.$ rotation $)$, and always occurred in a control (saline or sham) recording. This allowed us to compare the effects of a small configurational change with those of a bigger change. Subsequently, the rats were trained to run in 1-3 configuration for several days, so that it became familiar (the second familiar configuration). Two more novel recordings were obtained on arms adjacent to arm 3 (i.e., 2 and 4). The novel configuration was obtained either by moving one arm by either 51 or $154^{\circ}$ (to other side of the maze).
There was no differential effect of the large or small rotation on any of the place field characteristics (all $p>0.1$ ); therefore, the data were pooled.

Data recording and analysis

Single-unit data. Electrodes were lowered slowly into the brain $(<500$ $\mu \mathrm{m}$ daily), until hippocampal single units could be identified. Hippocampal units were recorded when the waveforms appeared stable (and at least 30 min after moving an electrode). During the recording session, the animals wore a multichannel headstage device that was connected to 
the recording apparatus through a fine wire bundle, which did not limit the animal's freedom of movement. The location and the head direction of the animals were recorded by an overhead tracking system, based on the position of two arrays of infrared and light emitting diodes that were attached to the headstage. The signal from the tetrodes was amplified 20005000 times (Neuralynx, Tucson, AZ), filtered between $300 \mathrm{~Hz}$ and $6 \mathrm{kHz}$, and stored for offline analysis. Individual units were isolated using a spike parameter cluster separation method. The clustering was based on the spike duration and the relative amplitude of the signals on the four electrode wires composing a tetrode (O'Keefe and Reece, 1993). The recording environment was divided into a $64 \times 64$ bin array consisting of $0.6 \times 0.6 \mathrm{~cm}$ squares. Firing rate maps were constructed for each cell using an adaptive smoothing method (Skaggs and McNaughton, 1998). Place fields were defined as an area of at least 15 bins sharing adjacent edges, with a firing rate per bin $>2$ SDs above the mean firing rate of the cell on the entire apparatus.

Place cells are directionally selective on linear track mazes (Markus et al., 1995). Accordingly, analyses of place fields were performed separately for inward and outward headings. Rate map correlations were calculated only for those regions of the apparatus that were visited at least three times at a minimum speed of $2.4 \mathrm{~cm} / \mathrm{s}$ in both rate maps. The velocity filter was used to ensure that all data were recorded while the rat was moving at a robust speed (i.e., in theta).

The identification of the type of cell (i.e., complex spike or interneuron) was based on the firing rate $(<2.5 \mathrm{~Hz}$ for complex spike cells) and the spike width $(>0.256 \mathrm{~ms})$. Furthermore, only place cells with a minimum firing rate of $0.25 \mathrm{~Hz}$ and showing spatial selectivity (i.e., at least one field) were included in the analyses. For both the familiar and novel configurations, two types of analyses were performed as follows:

(1) Firing and place field characteristics, such as mean firing rate, in-field firing rate, spatial information per spike, and sparsity. The spatial information per spike (information per spike) was calculated in terms of the spatial information content (in bits) a single spike conveys about the animal's location. Spatial information content of spike discharge was calculated using the following formula: information content $=\Sigma P_{i}\left(R_{i} / R\right) \log _{2}\left(R_{i} / R\right)$, where $i$ is the bin number, $P_{i}$ is the probability of occupancy of bin $i, R_{i}$ is the mean firing rate for bin $i$, and $R$ is the mean firing rate of the cell. The sparsity measures the fraction of the environment in which a cell is active (Skaggs et al., 1996).

(2) Place field stability was calculated by measuring the correlation between the firing rate maps of a cell before and after infusion, or across different intervals of a recording. To analyze the timeline of the place field changes, the 9 min recordings in the familiar configuration were divided into three intervals ( $a=0-3 \mathrm{~min}, b=3-6 \mathrm{~min}, c=6-9 \mathrm{~min}$ ), and the 12 min recordings in a novel configuration were divided in four intervals ( $a=0-3 \mathrm{~min}, b=3-6 \mathrm{~min}, c=6-9 \mathrm{~min}, d=9-12 \mathrm{~min}$ ). A prerequisite for performing a rate map correlation was a minimum of one place field (based on criteria above) during at least one of the intervals of a recording. The correlations were computed only if the cell fired at least 10 spikes in each interval and only for locations that were visited at least three times during the considered interval. The different rate maps were compared using Pearson correlations, computed on a bin-by-bin basis.

EEG data. At the end of the maze recordings, the effect of the septal
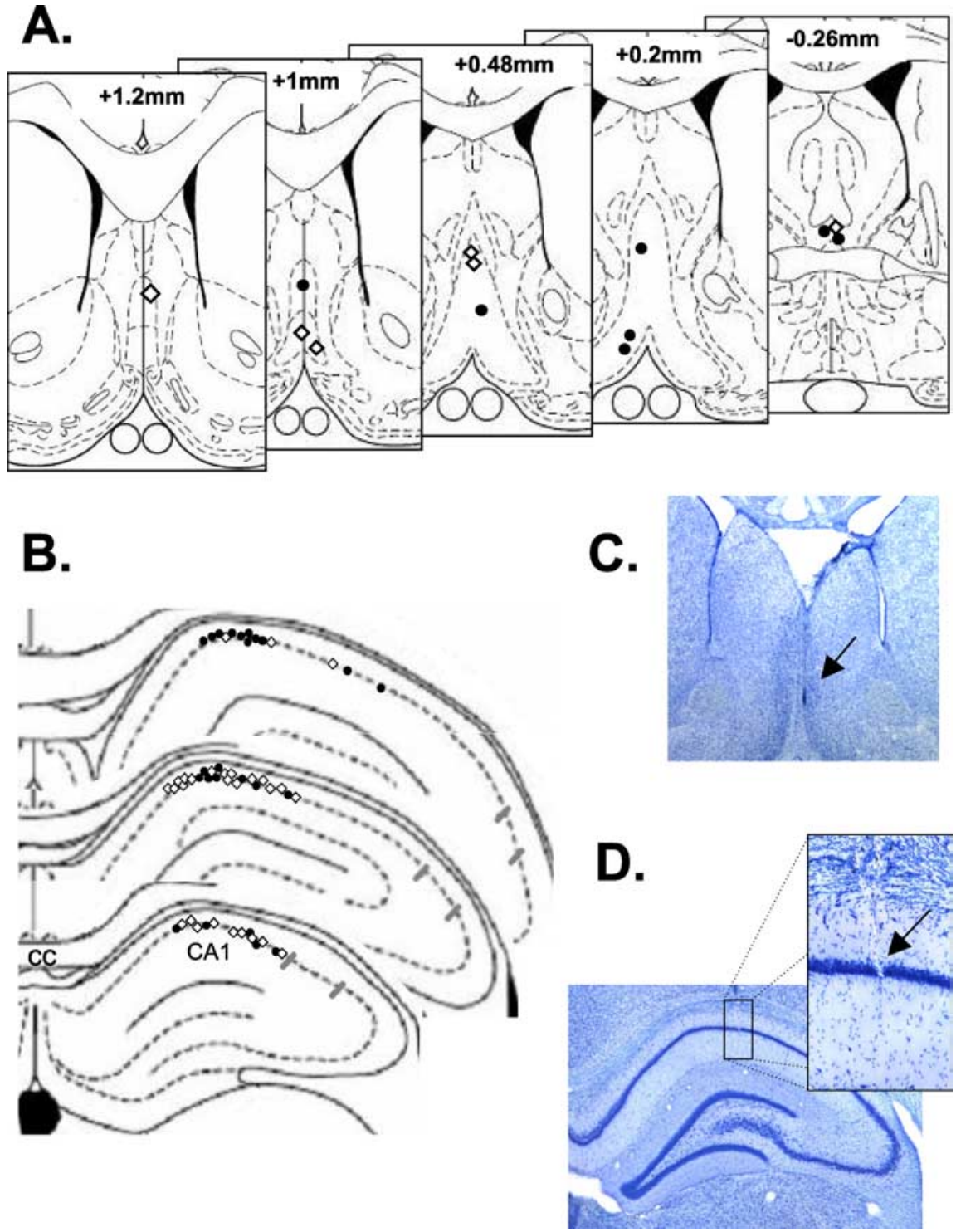

Figure 3. Injector locations and recording sites. Each injector location and recording site is marked with a black circle for young sections through dorsal hippocampus. The histological drawings in $\boldsymbol{A}$ and $\boldsymbol{B}$ are adapted from Paxinos and Watson (1998). C, Photograph of a histological section through the medial septum. The arrow marks the injector location. D, Photographs of a histological section through the dorsal hippocampus. The arrow marks the CA1 electrode location. CC, Corpus callosum.

carbachol infusion on hippocampal EEG was assessed as the rats were drinking (a behavior associated with low theta power) (Buzsaki et al., 1983; Bland, 1986; Stewart and Fox, 1990). Data for each rat were recorded over five sessions. Recordings were performed while the rats were drinking chocolate (Nesquik) in their home cage, and the power in the theta band was compared before and after carbachol infusion. The signal was amplified 200 times and filtered between $1 \mathrm{~Hz}$ and $3 \mathrm{kHz}$. The data were stored for off-line analyses using MatLab software. Theta epochs during drinking were detected by calculating the ratio of the theta (5-10 $\mathrm{Hz}$ ) and delta $(1-4 \mathrm{~Hz})$ frequency bands in $3.0 \mathrm{~s}$ windows (Csicsvari et al., 1999). Ten 3 s epochs ( 30 s total) with similar power in the delta band were analyzed for each recording session. The energy in the $6-12 \mathrm{~Hz}$ (theta) band was calculated for each 3 s epoch and averaged across the 10 epochs to obtain the average theta power for each recording; then, the five recordings from each rat were averaged.

\section{Statistical analysis}

All data were analyzed using parametric tests. The place field characteristics for the familiar recordings were analyzed using repeated-measures 
Table 1. Number of cells recorded by rat and condition

\begin{tabular}{|c|c|c|c|c|c|c|}
\hline Rat & $\begin{array}{l}\text { Familiar } \\
\text { carbachol }\end{array}$ & $\begin{array}{l}\text { Familiar } \\
\text { control }\end{array}$ & $\begin{array}{l}\text { Day } 1 \text { novel } \\
\text { carbachol }\end{array}$ & $\begin{array}{l}\text { Day } 1 \text { novel } \\
\text { control }\end{array}$ & $\begin{array}{l}\text { Day } 2 \text { novel } \\
\text { carbachol }\end{array}$ & $\begin{array}{l}\text { Day } 2 \text { novel } \\
\text { control }\end{array}$ \\
\hline \multicolumn{7}{|l|}{ Young } \\
\hline 116 & $30(30)$ & $2(2)$ & & $25(26)$ & & $15(15)$ \\
\hline 945 & $4(4)$ & $1(1)$ & & $2(8)$ & $1(1)$ & $5(6)$ \\
\hline 954 & $11(11)$ & $7(7)$ & $10(13)$ & $7(11)$ & $10(10)$ & $4(6)$ \\
\hline 956 & $1(1)$ & & $6(6)$ & $16(20)$ & $5(6)$ & $11(10)$ \\
\hline 965 & & $21(21)$ & $8(7)$ & & $5(5)$ & \\
\hline 996 & $3(3)$ & $23(23)$ & $18(24)$ & $11(12)$ & $4(4)$ & 17 (17) \\
\hline 997 & $4(4)$ & $28(28)$ & $25(23)$ & $10(11)$ & $16(11)$ & \\
\hline Total & $53(53)$ & $82(82)$ & $67(74)$ & $71(88)$ & $41(36)$ & $52(54)$ \\
\hline \multicolumn{7}{|l|}{ Old } \\
\hline 109 & & $4(4)$ & & & & \\
\hline 110 & & $5(5)$ & & $16(16)$ & & $10(9)$ \\
\hline 117 & $36(36)$ & $61(61)$ & $21(21)$ & $27(17)$ & 39 (37) & $11(10)$ \\
\hline 118 & $4(4)$ & $5(5)$ & $11(7)$ & $10(11)$ & 19 (14) & $3(5)$ \\
\hline 119 & $10(10)$ & $4(4)$ & & & & \\
\hline 120 & $4(4)$ & & 14 (14) & $11(9)$ & & $12(13)$ \\
\hline 961 & $1(1)$ & & & & & \\
\hline 972 & $12(12)$ & $27(27)$ & & $4(4)$ & & $2(2)$ \\
\hline Total & $67(67)$ & $106(106)$ & $46(42)$ & $68(57)$ & $58(51)$ & $38(39)$ \\
\hline
\end{tabular}

The first number in each cell represents the cells that met the criteria for inclusion in the statistical analysis for place field parameters. The numbers of cells that met the criteria for inclusion in the reliability analysis are in parentheses.

ANOVAs, with session (preinfusion and postinfusion) as the repeated factor, and age and drug as the between-subjects factors. For each day of novel recordings, the place field characteristics were analyzed using a two-way ANOVA (age by drug). The rate map correlations across different intervals of a recording were compared using two- or three-way ANOVAs. In addition, post hoc or $t$ tests were performed to confirm the cause of significant interactions. Only effects that were significant ( $p \leq$ $0.05)$ or showed a trend for significance $(0.05<p<0.1)$ are presented. All nonsignificant effects had $p>0.1$.

\section{Infusion procedure}

Carbachol was dissolved in saline to a concentration of $0.25 \mu \mathrm{g} / \mu \mathrm{l}$, resulting in a total dose of $0.125 \mu \mathrm{g}$. Infusers $1 \mathrm{~mm}$ longer than the cannula were connected through polyethylene tubing to a $10 \mu$ l Hamilton syringe. A Harvard Apparatus (Holliston, MA) 505 microinfusion pump was used to generate a constant flow of $0.125 \mu \mathrm{l} / \mathrm{min}$. Rats were infused for a total of $4 \mathrm{~min}$; the injector was left in place for 1 more minute to allow for diffusion. A total volume of $0.5 \mu \mathrm{l}$ was infused. The order of drug administration (carbachol and saline) was randomized between rats and infusions were separated by at least $3 \mathrm{~d}$, to allow for recovery. We also performed sham infusions as additional controls and to prevent additional tissue damage. The procedure was similar, with the difference that an infuser shorter than the cannula was used, and no fluid was injected. An analysis of the place field characteristics of cells recorded in the familiar and novel configuration of the maze showed no difference between saline or sham infusions (all $p>0.1$ ); therefore, the data from saline and sham infusions were pooled.

\section{Histology}

At the end of the recordings, the rats were killed with $\mathrm{CO}_{2}$ and transcardially perfused with $0.9 \%$ saline, followed by $3.7 \%$ paraformaldehyde. The brains were removed and stored in paraformaldehyde for at least $48 \mathrm{~h}$. Coronal sections $(50 \mu \mathrm{m})$ were cut using a vibratome, and then stained with thionin. Only rats with a good placement of the MS injector were included in the carbachol analysis. Electrode locations in the CA1 area were identified based on histological placement and electrode advancement records. Injector locations and electrode positions are shown in Figure 3. A summary of the number of cells recorded from each rat is presented in Table 1.

\section{Results}

The effect of MS infusions of $0.125 \mu \mathrm{g}$ of carbachol on hippocampal EEG was assessed while the animals were drinking chocolate- flavored water in their home cage (a behavior associated with low theta). There was a significant increase in theta power during drinking postinfusion, compared with the preinfusion EEG, for both young and old rats $\left(t\right.$ tests, $t_{(6)}=3.282, p=0.017$; $t_{(5)}=3.297, p=0.03$, respectively), although no age effect was observed $(p>$ 0.1 ) (Fig. 4). Carbachol infusions into the MS also caused a decrease in running speed in the familiar, but not the novel maze configuration (supplemental Fig. 1, available at www.jneurosci.org as supplemental material).

The data were analyzed by cell; in addition, the data were collapsed and analyzed by animal. The by-animal analysis showed similar results despite reduced statistical power (supplemental Table 1, available at www.jneurosci.org as supplemental material).

\section{Age and carbachol effects in the familiar configuration}

Place cells were recorded as the rats alternated between feeders at the end of two maze arms (Fig. $1 A$ ). This procedure provided information on the hippocampal representation of the familiar configuration of the maze. Rats were then removed from the maze room and given a carbachol or control infusion, after which they were placed back on the maze. Examples of preinfusion and postinfusion CA1 place field activity are shown in Figure $1 B-E$.

The firing rate (Fig. 5A) was higher in the postinfusion recording session, as revealed by a session effect [repeated-measures ANOVA (RM-ANOVA), $\left.F_{(1,304)}=28.362, p<0.001\right]$. In addition, firing rates were higher in the young animals $\left(F_{(1,304)}=\right.$ $10.211, p=0.002)$. The age by session interaction was not significant $\left(F_{(1,304)}=3.477, p=0.063\right)$. This effect of age on CA1 neurons firing rate has been found in some studies (Shen et al., 1997), but not in others (Oler and Markus, 2000; Wilson et al., 2005). There were no other age-related differences in the familiar configuration (all $p>0.1$ ) (Table 2).

Carbachol disrupted the place-specific firing of cells in both young and old rats. Carbachol did not affect the mean firing rate, but decreased the in-field firing rate of neurons, particularly in young rats (RM-ANOVA, session by drug interaction, $F_{(1,304)}=$ $26.534, p<0.001 ; t$ test, $t_{(52)}=2.945, p<0.005$ for young rats; $p>0.1$ for old). Carbachol also decreased the spatial information carried by each spike (RM-ANOVA, session by drug interaction, $F_{(1,304)}=46.547, p<0.001 ; t$ test, $t_{(52)}=5.996, p<0.001$ for young rats; $t_{(66)}=4.735, p<0.001$ for old rats) (Fig. $5 B$ ). The total firing area (i.e., sparsity) was larger after carbachol than after control infusions (session, $F_{(1,304)}=26.076, p<0.001$; session by drug interaction, $F_{(1,304)}=21.133, p<0.001$; also $t$ tests comparing carbachol to control, $t_{(52)}=4.303, p<0.001$ for young, and $t_{(66)}=4.487, p<0.001$ for old rats) (Table 2). These results suggest that the firing characteristics of hippocampal CA1 neurons were mostly unaffected by aging, and that carbachol decreased the spatial tuning of CA1 neurons.

The correlation between the firing rate maps before and after infusion was calculated for each cell to assess the stability of the place field representation (Fig. 5C) (also Fig. 1B-E). Under control conditions, the correlation was high for both old and young 

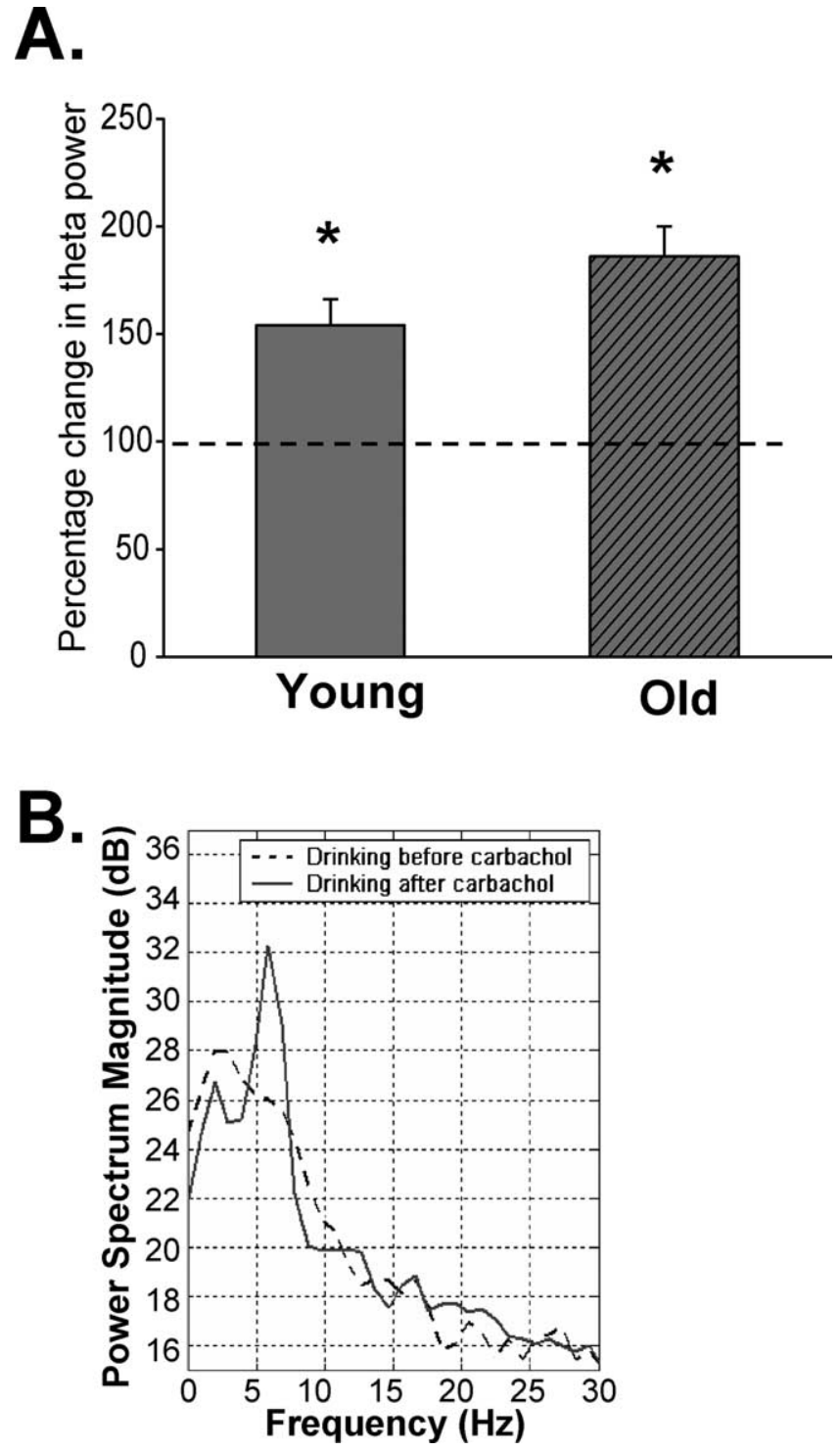

Figure 4. Carbachol-induced changes in hippocampal theta power. Five recordings were performed while the rats were drinking chocolate-flavored water (Nesquik) in their home cage, and the power in the theta band was compared before and after carbachol infusion. The signal was amplified 200 times and filtered between $1 \mathrm{~Hz}$ and $3 \mathrm{kHz}$. The data were stored for off-line analyses using MatLab software. Ten 3 s epochs of EEG data ( 30 s total) were analyzed for each recording session. The energy in the $6-12 \mathrm{~Hz}$ (theta) band was calculated for each 3 s epoch and averaged across the 10 epochs to obtain the average theta power for each recording. Then, the five recordings from each rat were averaged. Ten epochs for the preinfusion and postinfusion recordings were chosen so that they have similarly low energy in the $1-4 \mathrm{~Hz}$ band. Theta power increases after carbachol infusion. $A$, Average increase in the theta power in the postcarbachol recording relative to the precarbachol recording. Error bars represent means \pm SEM. The asterisks represent significant difference from preinfusion recordings ( $100 \%$ line means no change in theta power after carbachol infusion). $\boldsymbol{B}$, Example of power spectrum densities for one preinfusion and one postinfusion recording. After carbachol infusion, there is a large increase in theta power.

rats (correlations of $r=0.75$, and $r=0.7$, respectively). Carbachol decreased the correlations (ANOVA, $F_{(1,304)}=26.779, p<$ $0.001 ; t$ test for young rats, $t_{(153)}=3.408, p=0.001 ; t$ test for old rats, $\left.t_{(171)}=3.933, p<0.001\right)$. There was no age difference and no age by drug interaction with respect to pre-post infusion correlations (ANOVA, both $p>0.1 ; t$ tests comparing young and old rats for the control and carbachol conditions, $p>0.1$ ), which suggests that carbachol decreased the stability of fields similarly
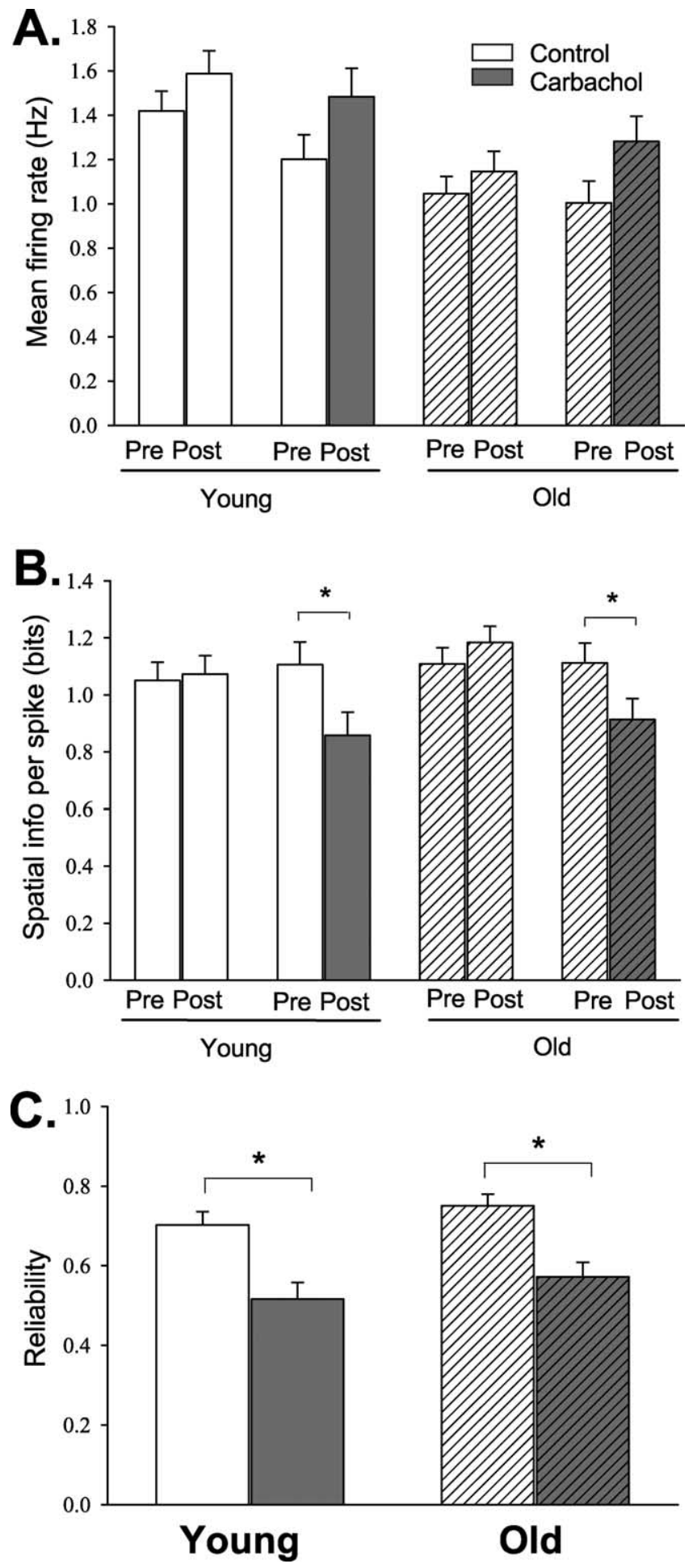

Figure 5. Firing characteristics and reliability of CA1 place cells in the familiar configuration. $A$, Mean firing rate was higher for the young than for the old rats, and was also higher in the postinfusion recording than in the preinfusion recording. $\boldsymbol{B}$, The spatial information content was lower after carbachol infusions for both young and old rats. Pre, Preinfusion recording; Post, postinfusion recording. $C$, Under control conditions, the reliability of place fields is high for both young and old rats. Carbachol decreased the reliability of place fields for both age groups. Error bars represent means $\pm S E M$. *Significant differences between carbachol and control conditions $(p \leq 0.001)$.

in both age groups. When the data were analyzed by 3 min intervals, we found that place fields remained unstable over the whole duration of the postcarbachol recording (see supplemental Re- 
Table 2. Firing characteristics of hippocampal principal cells: familiar environment

\begin{tabular}{|c|c|c|c|c|c|c|c|c|c|}
\hline & \multirow[b]{3}{*}{ Significance } & \multicolumn{4}{|l|}{ Young } & \multicolumn{4}{|l|}{ Old } \\
\hline & & \multicolumn{2}{|l|}{ Control } & \multicolumn{2}{|l|}{ Carbachol } & \multicolumn{2}{|l|}{ Control } & \multicolumn{2}{|l|}{ Carbachol } \\
\hline & & Pre & Post & Pre & Post & Pre & Post & Pre & Post \\
\hline Firing rate $(\mathrm{Hz})$ & $\begin{array}{l}A: F_{(1,304)}=10.211, p=0.002 ; S: \\
\quad F_{(1,304)}=28.362, p<0.001 ; \\
\quad A \times S: F_{(1,304)}=3.477, p=0.063\end{array}$ & $1.42 \pm 0.09$ & $1.59 \pm 0.10$ & $1.20 \pm 0.11$ & $1.48 \pm 0.13$ & $1.05 \pm 0.08$ & $1.15 \pm 0.09$ & $1.00 \pm 0.10$ & $1.28 \pm 0.11$ \\
\hline In-field rate (Hz) & $\begin{array}{l}\mathrm{D}: F_{(1,304)}=6.956, p=0.009 \\
\quad \mathrm{D} \times \mathrm{S}: F_{(1,304)}=26.534, p<0.001\end{array}$ & $6.69 \pm 0.51$ & $7.54 \pm 0.57$ & $6.38 \pm 0.63$ & $4.95 \pm 0.71$ & $6.10 \pm 0.45$ & $7.46 \pm 0.5$ & $5.68 \pm 0.56$ & $5.11 \pm 0.63$ \\
\hline Info per spike (bits) & $\begin{array}{l}S: F_{(1,304)}=19.327, p<0.001 \\
\quad D \times S: F_{(1,304)}=46.547, p<0.001\end{array}$ & $1.05 \pm 0.06$ & $1.07 \pm 0.07$ & $1.11 \pm 0.08$ & $0.86 \pm 0.08$ & $1.11 \pm 0.06$ & $1.18 \pm 0.06$ & $1.11 \pm 0.07$ & $0.91 \pm 0.07$ \\
\hline Sparsity & $\begin{array}{l}S: F_{(1,304)}=26.076, p<0.001 \\
\quad D \times S: F_{(1,304)}=21.133, p<0.001\end{array}$ & $0.38 \pm 0.02$ & $0.39 \pm 0.02$ & $0.37 \pm 0.02$ & $0.45 \pm 0.03$ & $0.36 \pm 0.02$ & $0.36 \pm 0.02$ & $0.36 \pm 0.02$ & $0.41 \pm 0.02$ \\
\hline
\end{tabular}

Numbers represent means \pm SEM. Significance levels were yielded by repeated-measures ANOVA. A, Age; $D$, drug; S, session.

sults and supplemental Fig. 2, available at www.jneurosci.org as supplemental material).

Together, the data suggest no age-related differences in the firing properties in a familiar configuration. Septal activation with carbachol decreased the spatial tuning and stability of place fields for both young and old rats.

\section{Carbachol effects during the first exposure to a novel configuration}

Place cells were recorded as the rats ran in a novel configuration of the maze (Fig. 2A).

Running in a novel configuration resulted in decreased placespecific firing compared with running on the familiar maze configuration (see supplemental Results and supplemental Fig. 1, available at www.jneurosci.org as supplemental material). This decrease could be attributable to place fields appearing, disappearing, or changing their firing location over the course of the recording.

Under control conditions, neurons of aged rats had lower spatial information content per spike $\left(t\right.$ test, $t_{(137)}=4.41, p<$ $0.001)$ (Fig. $6 B)$, higher sparsity $\left(t_{(137)}=-3.727, p<0.001\right)$, and lower in-field rate $\left(t_{(137)}=2.031, p=0.043\right)$, suggesting that old rats had less specific place fields than young rats in the novel configuration. A two-way ANOVA revealed that the mean firing rate was higher in the aged rats $\left(F_{(1,251)}=4.774, p=0.03\right)$, and there was no effect of carbachol or interaction between age and carbachol (Fig. 6A). Carbachol decreased the in-field rate in young rats (age by drug interaction: $F_{(1,251)}=9.688, p=0.002 ; t$ test, $\left.t_{(136)}=2.985, p=0.003\right)$. The spatial information content was lower for old rats than for young rats (ANOVA, $F_{(1,251)}=$ 9.249, $p=0.003)$; although there was a significant age by drug interaction $\left(F_{(1,251)}=3.948, p=0.048\right)$ (Fig. $\left.6 B\right)$ for the spatial information content, post hoc analyses showed that carbachol did not significantly change the information content for either young or old rats. The spatial sparsity was higher for old rats than for young rats during the first exposure to the novel configuration (age effect on sparsity, $F_{(1,251)}=9.87, p=0.003$ ), and carbachol did not affect the sparsity (all $p>0.1$ ) (Table 3). Together, these results suggest that carbachol had limited effects on the firing properties of CA1 neurons in a novel configuration, and young rats were more affected than old rats.

To examine the temporal dynamics of the place field response, the $12 \mathrm{~min}$ of novel configuration recording were divided into four intervals ( $a=0-3 \mathrm{~min} ; b=3-6 \mathrm{~min} ; c=6-9 \mathrm{~min} ; d=9-12$ $\mathrm{min}$ ), and place field correlations were computed between adjacent intervals (Fig. $7 A, B$ ) (for examples, see Fig. 2B). In young animals after control infusions, the correlation was high and did
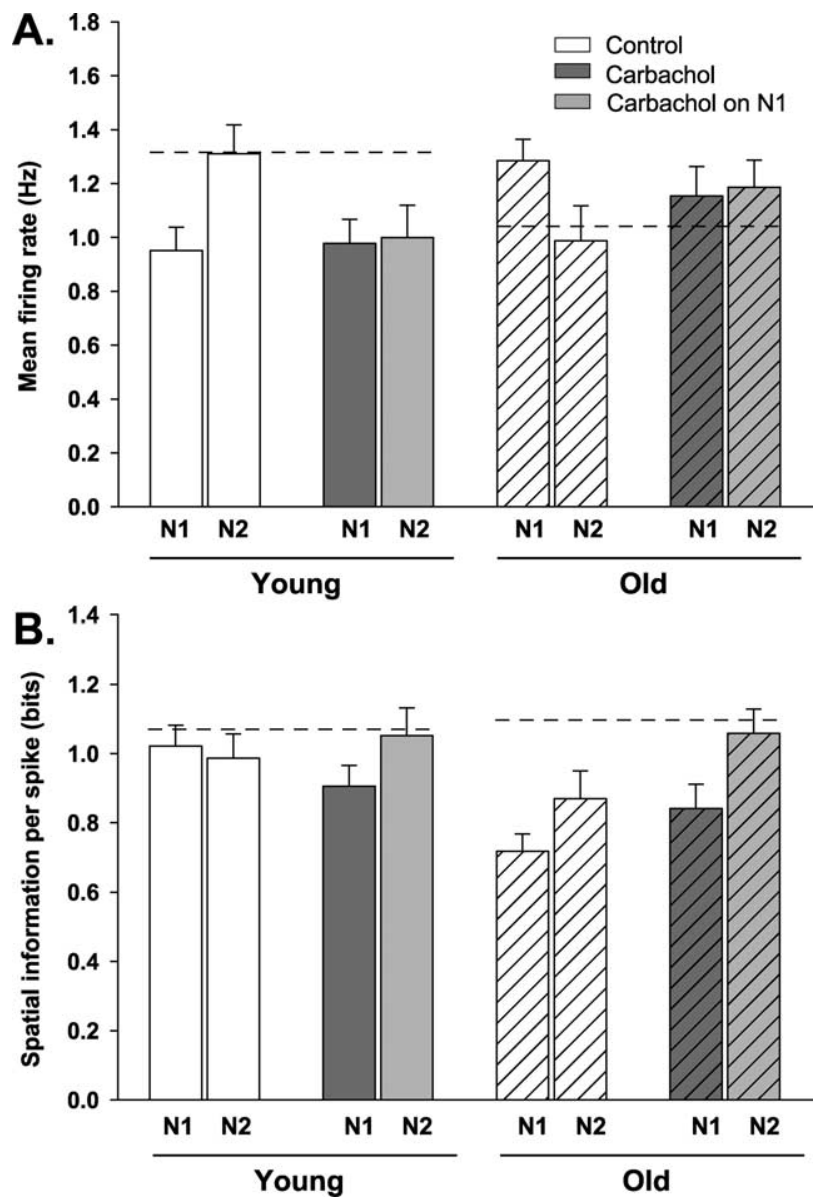

Figure 6. Firing characteristics of CA1 pyramidal cells during the two exposures to the novel configuration. $A$, The mean firing rate in control recordings was lower for young rats and higher for old rats during the first exposure to the novel configuration, but by the second day the values were similar to the familiar configuration. For rats that received carbachol before the first exposure to the novel configuration, the overall firing rate was similar during the two novel exposures. B, Spatial information content was lower in old than in young rats. Carbachol decreased the spatial information content for young rats during the first exposure to the novel, but increased it for old rats. N1, First exposure to the novel configuration; N2, second exposure to the novel configuration. The dashed line represents the averaged values of the firing rate and spatial information content for the preinfusion recordings in a familiar configuration. Error bars represent means \pm SEM.

not change over the course of the entire recording (ANOVA, $p>$ 0.1 ). Conversely, place fields of old rats were initially unstable and became more stable over the course of the recording. After control infusions, the $a$ to $b$ correlation was lower for aged rats than 
Table 3. Firing characteristics of hippocampal principal cells: first exposure to novel configuration

\begin{tabular}{|c|c|c|c|c|c|}
\hline & & Young & & Old & \\
\hline & Significance & Control & Carbachol & Control & Carbachol \\
\hline Firing rate $(\mathrm{Hz})$ & $\mathrm{A}: F_{(1,265)}=7.696, p=0.006$ & $0.95 \pm 0.09$ & $0.98 \pm 0.06$ & $1.28 \pm 0.08$ & $1.15 \pm 0.11$ \\
\hline In-field rate (Hz) & $\mathrm{A} \times \mathrm{D}: F_{(1,265)}=6.735, p=0.01$ & $4.86 \pm 0.35$ & $3.51 \pm 0.36$ & $4.19 \pm 0.32$ & $4.75 \pm 0.43$ \\
\hline Information per spike (bits) & $\begin{array}{l}\mathrm{A}: F_{(1,265)}=9.9, p=0.002 \\
\quad \mathrm{~A} \times \mathrm{D}: F_{(1,265)}=4.214, p=0.041\end{array}$ & $1.02 \pm 0.06$ & $0.91 \pm 0.06$ & $0.72 \pm 0.05$ & $0.84 \pm 0.07$ \\
\hline Sparsity & $\mathrm{A}: F_{(1,265)}=9.348, p=0.002$ & $0.37 \pm 0.02$ & $0.42 \pm 0.02$ & $0.46 \pm 0.02$ & $0.46 \pm 0.03$ \\
\hline
\end{tabular}

Numbers represent means \pm SEM. Significance levels were yielded by two-way ANOVA. A, Age; D, drug; S, session.

for young rats (ANOVA, $F_{(1,142)}=4.342, p$ $=0.039)$, although it continued to improve over the course of the recording (ANOVA, $\left.F_{(2,167)}=5.205, p=0.006\right)$. For young rats, the stability of fields was lower after carbachol than after control infusions $\left(\right.$ ANOVA, $\left.F_{(1,481)}=21.854, p<0.001\right)$, particularly in the first $6 \mathrm{~min}$ in the novel configuration ( $t$ test for $a b$ interval pair, $t_{(157)}=4.336, p<0.001$; for $c d$ interval pair, $\left.t_{(159)}=2.06, p=0.041\right)$. For old rats, carbachol tended to increase the place field correlations (ANOVA, $F_{(1,293)}=3.476, p$ $=0.063)$, specifically during the beginning of the recording ( $t$ test for $a b$ interval pair, $\left.t_{(96)}=1.852, p=0.067\right)$. Therefore, carbachol had little effect on the basic firing properties of cells, while altering the place field dynamics. There was an age-related differential effect: carbachol decreased the stability of fields in the young rats, whereas it tended to increase the stability of fields for the old rats.

\section{No significant correlation between the running speed and the firing rate maps correlations}

As previously noted, carbachol increased the latency per trial for young rats during the alternation task in the novel configuration. Therefore, the low place field stability during the first $3 \mathrm{~min}$ of the postcarbachol infusion in young rats could be attributable to the decreased running speed at the beginning of postinfusion recording. To investigate this, we calculated Pearson correlations of the number of trials completed in the first 3 min to the cells' firing map correlation values for the $a b$ interval pair. All correlations were nonsignificant and $<0.203$; therefore, the decreased stability of place cells of young rats after carbachol infusions does not seem to be the result of changed running speed (Fig. 8).

To summarize, the spatial firing characteristics and the place field stability data suggest that place cells of old rats show a smaller and slower response to the novel configuration; carbachol impairs place-specific firing in young rats, but facilitates it in old rats.

\section{Second exposure to the novel configuration}

One day after the initial exposure to the novel configuration, the rats were run through the same sequence for a second time, but 0.001). ${ }^{\#} 0.05<p<0.1$.
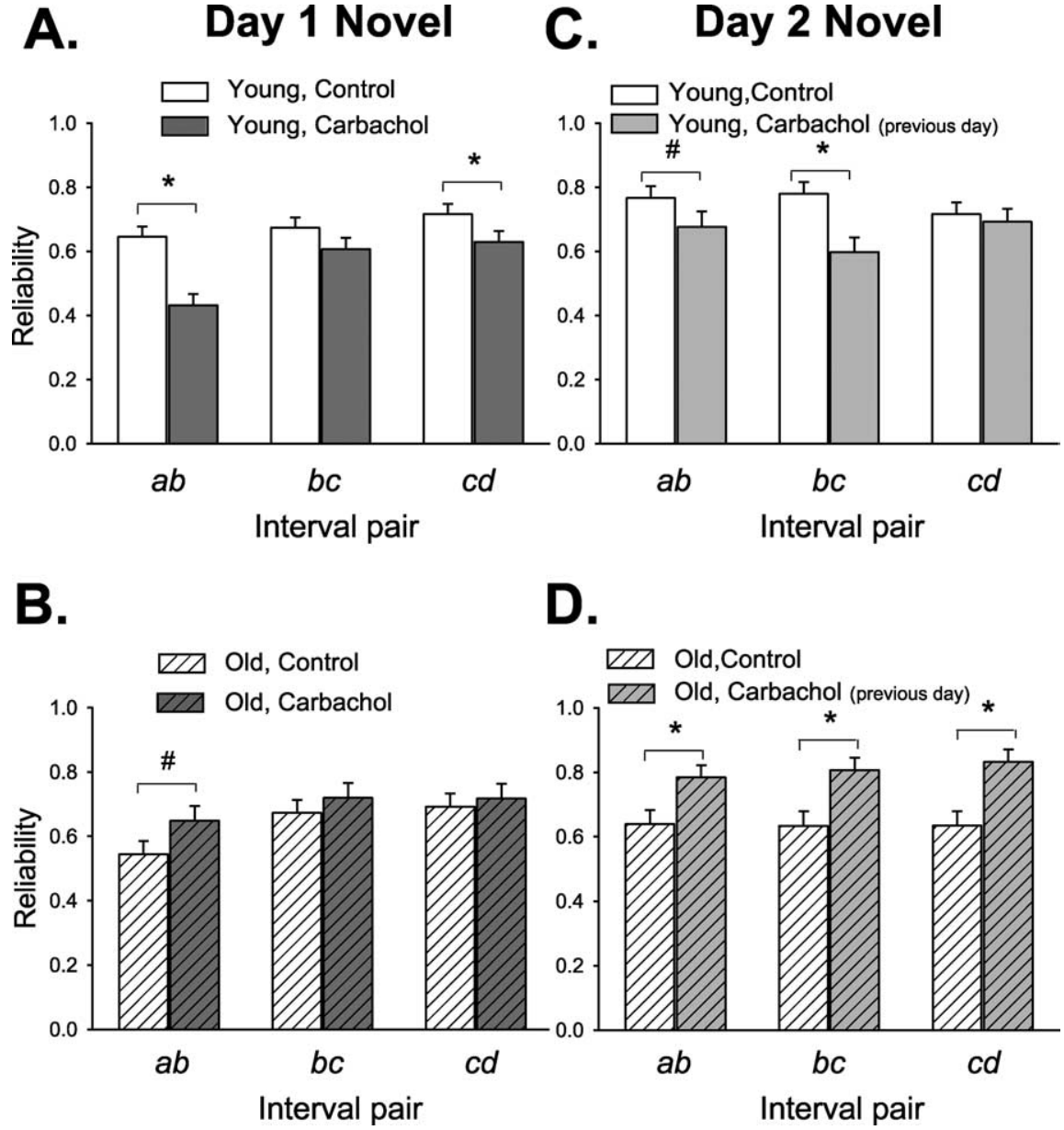

Figure 7. Place field reliability in the novel configuration. The novel recording was divided into four 3 min intervals $(a=0-3$ $\min ; b=3-6 \mathrm{~min} ; c=6-9 \mathrm{~min} ; d=9-12 \mathrm{~min}$ ) and reliability was calculated for adjacent intervals. $A, B$, Place field reliability during the first exposure to the novel configuration for young $(\boldsymbol{A})$ and old $(\boldsymbol{B})$ rats. In young rats, carbachol decreased the reliability of fields. For old rats, carbachol increased the reliability of fields. $C, D$, Place field reliability during the second exposure to the novel environment for young $(\boldsymbol{C})$ and old $(\boldsymbol{D})$ rats. Young rats that experienced the novel configuration under carbachol the first day had lower reliability values. Conversely, the reliability was higher for old rats that had carbachol during the first exposure to the novel configuration. Error bars represent means \pm SEM. *Significant differences between carbachol and control conditions ( $p<$

no carbachol was infused (Fig. 9). During the reintroduction to the novel maze configuration, the mean firing rate (Fig. $6 A$ ) was differently affected, depending on age and whether carbachol was administered during the initial exposure to the maze (age by drug interaction, $\left.F_{(1,188)}=4.966, p=0.027\right)$. However, $t$ tests showed no significant difference in firing rate between rats that received control or carbachol infusions, for either young or old rats. A two-way ANOVA for the in-field firing rate of pyramidal cells also yielded a significant interaction of drug and age $\left(F_{(1,188)}=\right.$ 5.881, $p=0.016$ ). The interaction was mainly attributable to a lower in-field firing rate in young rats that received carbachol the 


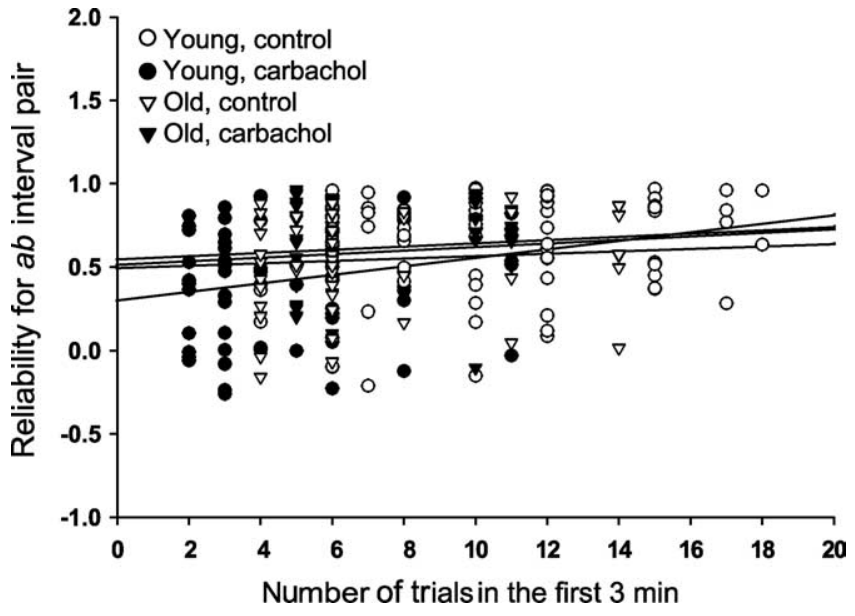

Figure 8. Relationship between the place field reliability and number of trials completed. Pearson's correlations were calculated between the reliability of place fields for $a b$ intervals and the number of trials completed during the first 3 min of running in the first exposure in the novel configuration. The correlations were nonsignificant for all experimental groups.

day before, compared with the young rats that received control infusions ( $t$ test, $t_{(136)}=2.985, p=0.003$ ), whereas the old rats had similar mean firing rates regardless of the type of infusion. The main effects (age and drug) were not significant for the mean and in-field firing rates. Together, the effects on the firing rates suggest that firing of pyramidal neurons was more spatially disorganized in young rats than in old rats after carbachol infusions (i.e., lower in-field:mean firing rate ratio).

The spatial information content tended to be higher $\left(F_{(1,188)}\right.$ $=3.143, p=0.078$ ) (Fig. $6 B$ ) and the sparsity tended to be lower $\left(F_{(1,188)}=3.09, p=0.08\right)$ in rats that received carbachol the previous day. There was no age difference or age by drug interaction for spatial information content and sparsity (all $p>0.1$ ) (Table 4).

As with the first day in the novel configuration, the 12 min of the second exposure to the novel configuration were divided into four intervals, and correlations of the firing rate maps were computed between adjacent intervals. As can be seen in Figure 7, C and $D$, the manner in which the novel configuration was initially experienced (i.e., after carbachol or control infusions) affected the stability of fields during the subsequent exposure to the same configuration. Young rats that received carbachol during the first day of novel exposure had less reliable place fields on the subsequent exposure; conversely, if aged rats experienced the novel configuration under carbachol, they showed more stable fields the following day (age by drug interaction, $F_{(1,1073)}=4.701, p<$ 0.001 ; $t$ test comparing the effects of carbachol and control infusions: $t_{(539)}=3.837, p<0.001$ for young rats, $t_{(531)}=7.881, p<$ 0.001 for old rats). For young rats that had carbachol the previous day, place fields were initially unstable; stability increased over the course of the recording, and it was similar to the control condition during the second half of the recording (ANOVA for $a b$ interval pair, $F_{(1,85)}=3.097, p=0.089$; for $b c$ interval pair, $F_{(1,91)}=9.0, p=0.003$; for $c d$ interval pair, $\left.p>0.1\right)$. For aged rats that received carbachol the previous day, stability of fields remained high throughout the recording session (ANOVA for $a b$ interval pair, $F_{(1,89)}=8.022, p=0.006$; for $b c$ interval pair, $F_{(1,87)}$ $=12.539, p=0.001$; for $c d$ interval pair, $F_{(1,87)}=13.781, p<$ $0.001)$.

To summarize, the data demonstrate that, for young rats, MS activation during the first exposure to a novel configuration im- paired place-specific firing of pyramidal neurons during a subsequent exposure to the same configuration. However, MS activation during the first exposure to a novel configuration improved the spatial firing of neurons in aged rats during the subsequent exposure.

\section{Is the remapping during the novel configuration limited to the rotated arm?}

To address this question, we correlated the firing of pyramidal cells during the familiar recording that preceded the arm rotation to the firing after the arm rotation. The correlations of the firing rate maps were calculated only for the familiar arm (i.e., the arm that remained in the same location in the novel configuration). During the first exposure to the novel configuration, the correlation of spatial firing on the familiar arm of the maze was lower than during the familiar recording, suggesting that the fields on the familiar arm were also affected by the arm rotation (Fig. 10 A). This was true for both age groups, after control $\left(t\right.$ tests, $t_{(162)}=$ $6.878, p<0.001$ for young; $t_{(158)}=7.255, p<0.001$ for old) and carbachol recordings $\left(t_{(121)}=4.137, p<0.001\right.$ for young; $t_{(107)}=$ $2.524, p=0.013$ for old). The correlation of spatial firing on the familiar arm of the maze before and after the arm rotation was not different between cells recorded after control and carbachol infusions, for either the young or the old rats (both $p>0.1$ ), suggesting that carbachol did not affect the amount of remapping on the familiar arm. However, old rats showed higher correlations after arm rotation than young rats $\left(F_{(1,247)}=4.802, p=\right.$ $0.029)$, which suggests that the place fields were more similar after arm rotation for old than for young rats. Also, the similarity of place fields on the familiar arm was higher than zero after arm rotation ( $0.328 \pm 0.022$ for young; $0.459 \pm 0.025$ for old); therefore, the remapping on the familiar arm was not total, but partial.

During the second day of exposure to the novel configuration, the correlation of place fields on the familiar arm before and after arm rotation was still lower than in a familiar environment for young rats $\left(t\right.$ tests, $t_{(135)}=5.741, p<0.001$ for control; $t_{(96)}=$ 2.505, $p=0.014$ for carbachol). For old rats, the correlation of place fields on the familiar arm after arm rotation was lower than in a familiar environment after control infusions $\left(t_{(143)}=4.492\right.$, $p<0.001)$, but not after carbachol infusion $(p>0.1)$ (Fig. $10 B)$. Moreover, the old rats that received carbachol before the first exposure to the novel configuration showed a trend for increased correlation of the firing on the familiar arm from the first to the second exposure to the novel $\left(t_{(91)}=1.746, p=0.084\right)$, whereas there was no difference in correlation for the young rats or the old rats that received control infusions. Similar to the first exposure to the novel configuration, the correlation of fields before and after arm rotation was higher for old rats than for young rats $\left(F_{(1,189)}=9.347, p=0.003\right)$.

To investigate the timeline of changes on the familiar arm of the maze, we divided the novel recording into four 3 min intervals and calculated the correlation of the firing maps for each novel interval to the firing map of the familiar maze. We found that the correlation did not change over the course of the novel recording for either the first or the second exposure to the novel configuration (all $p>0.1$ ), suggesting that the changes in place-specific firing occurred fast, within the first $3 \mathrm{~min}$ of exposure to the novel configuration.

\section{Discussion}

This paper examines how the MS modulates the place cell remapping in the hippocampus. Placing the animals into a familiar environment presumably determined the retrieval of a previously 
stored representation of that environment. Introduction to a novel configuration of the environment induced the formation of a new representation. MS activation (with carbachol) had different effects under familiar and novel conditions. In young animals, carbachol always caused instability of the hippocampal representation, whereas in aged animals carbachol caused instability in a familiar environment but improved the development of a representation under conditions of novelty.

\section{Familiar environment versus novel configuration}

Our results are in agreement with previous findings that in a familiar/stable environment place fields remain stable across repeated exposures to that environment (O'Keefe and Nadel, 1978; Thompson and Best, 1990). Place fields were highly correlated between two sessions in the environment despite the animals being removed from the room and undergoing control infusions. Experiencing a novel configuration of the maze resulted in a rapid remapping of place fields, with even the familiar section of the maze showing some remapping (Fig. 10). These results are in agreement with previous reports of remapping in response to changes in the environment (Cressant et al., 2002), task requirements (Oler and Markus, 2000), and exposure to a new region (Wilson and McNaughton, 1993) or maze configuration (Frank et al., 2004).

Thus, in the current study, the familiar environment caused retrieval, whereas the novel configuration caused the formation of a new representation.

\section{No age-related differences in the representation of a familiar environment}

Aging is characterized by multiple changes in hippocampal neurobiology, including decreased septal cholinergic projection to the hippocampus (Gill and Gallagher, 1998), decreased entorhinal cortex (EC) projection to the dentate gyrus (Barnes and McNaughton, 1980) and CA3 (Smith et al., 2000), reduction of specific classes of hippocampal GABAergic interneurons (Potier et al., 2006), and decreased synaptic plasticity (Foster, 1999). Despite these age-related changes, place fields of old rats are stable in familiar environments (Markus et al., 1994; Oler and Markus, 2000; Wilson et al., 2004, 2005) (however, note Barnes et al., 1997). Similarly, the current study found no effect of age on place field reliability or spatial tuning in the familiar environment, suggesting that the ability to retrieve and reliably hold a previously stored representation of the environment was mostly unaffected by aging.

\section{Age-related impaired encoding}

In contrast with the preserved ability to retrieve a stored representation, we found an age-related decrease in the ability to form a new representation. In agreement with previous reports of less remapping in aged animals (Tanila et al., 1997; Oler and Markus, 2000; Wilson et al., 2004), old rats showed less stable place fields during the first exposure to the novel configuration, and less remapping of place fields in the familiar half of the maze. Place fields of aged rats were also less specific (lower information content and higher sparsity). Because this is not always the case (Wilson et al., 2005), presumably the lower spatial specificity was the result of the reduced stability of the fields in the novel configuration.

\section{Effects of MS activation in a familiar environment}

The septo-hippocampal GABAergic neurons provide rhythmic disinhibitory input regulating hippocampal theta (Chrobak and Buzsaki, 1996). MS infusions of carbachol excite GABAergic neurons directly by activating muscarinic receptors (Alreja et al., 2000; Wu et al., 2000) and indirectly by activating nicotinic receptors on septal glutamatergic neurons (Wu et al., 2003). The current carbachol dose $(0.125 \mu \mathrm{g})$ was high enough to induce 
Table 4. Firing characteristics of hippocampal principal cells: second exposure to novel configuration

\begin{tabular}{|c|c|c|c|c|c|}
\hline & \multirow[b]{2}{*}{ Significance } & \multicolumn{2}{|l|}{ Young } & \multicolumn{2}{|l|}{ Old } \\
\hline & & Control & Carbachol & Control & Carbachol \\
\hline Firing rate $(\mathrm{Hz})$ & $\mathrm{A} \times \mathrm{D}: F_{(1,188)}=4.966, p=0.027$ & $1.31 \pm 0.11$ & $1.00 \pm 0.12$ & $0.99 \pm 0.13$ & $1.19 \pm 0.10$ \\
\hline In-field rate $(\mathrm{Hz})$ & $\mathrm{A} \times \mathrm{D}: F_{(1,188)}=5.881, p=0.016$ & $5.91 \pm 0.61$ & $4.99 \pm 0.68$ & $4.30 \pm 0.71$ & $6.52 \pm 0.58$ \\
\hline Information per spike (bits) & $\mathrm{D}: F_{(1,188)}=3.143, p=0.078$ & $0.99 \pm 0.07$ & $1.05 \pm 0.08$ & $0.87 \pm 0.08$ & $1.06 \pm 0.06$ \\
\hline Sparsity & $\mathrm{D}: F_{(1,188)}=3.09, p=0.08$ & $0.39 \pm 0.02$ & $0.36 \pm 0.03$ & $0.42 \pm 0.03$ & $0.37 \pm 0.02$ \\
\hline
\end{tabular}

Numbers represent means \pm SEM. Significance levels were yielded by two-way ANOVA. A, Age; D, drug; S, session.

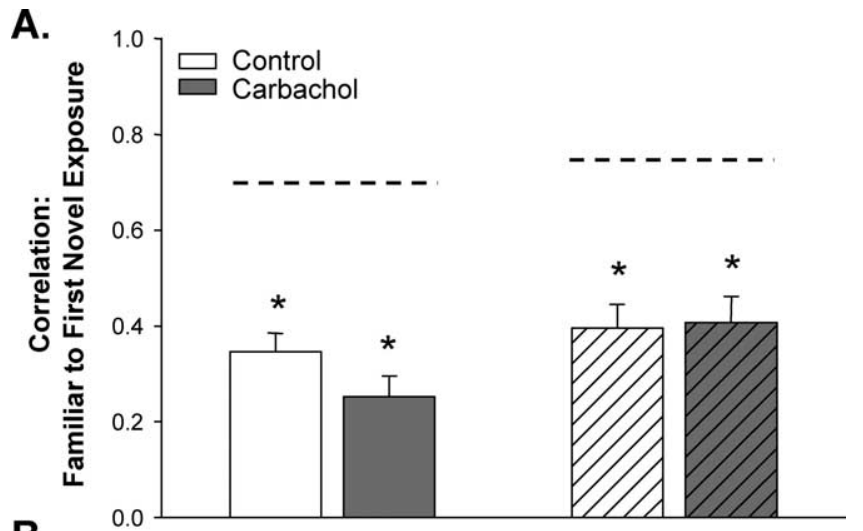

B.

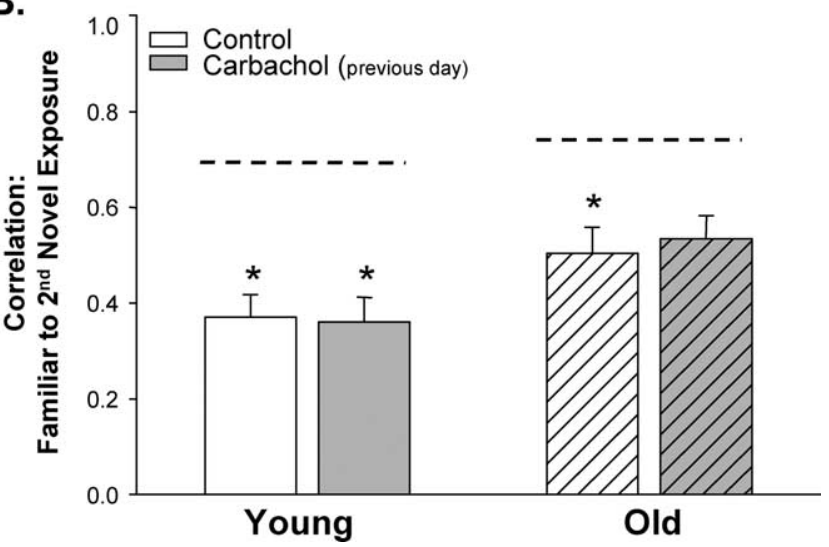

Figure 10. Correlations of the firing rate maps between the familiar and the novel maze configurations for the unmoved section of the maze (familiar arm), by age and condition. $A$, Correlation on the first exposure to the novel configuration. $\boldsymbol{B}$, Correlation on the subsequent day (i.e., the second exposure to the novel configuration). On both days, place fields on the unmoved part of the maze were more affected by the configuration change in young than in old rats. The dashed lines represent the correlations under control conditions for repeated exposures to the familiar maze (Fig. 50). Error bars represent means $\pm S E M$. * Significant differences between carbachol and control conditions ( $p \leq 0.014)$.

theta during a nontheta behavior (drinking), and it was below the level that induces seizures (no cases observed) (Sabolek et al., 2004b). The same MS carbachol dose disrupted memory in young rats performing a hippocampal delayed-non-match-tosample radial maze task (Bunce et al., 2004a,b).

The increased MS activity induced by this low dose of carbachol was enough to impact place fields in both aged and young animals. MS activation decreased the ability of the hippocampus to retrieve and hold the stored representation of the familiar environment; it also increased latency per trial, possibly because of increased exploration.

There are no previous studies examining the effects of MS activation on hippocampal place fields. However, studies using inactivation or lesions of the MS (Mizumori et al., 1989; Leutgeb and Mizumori, 1999; Ikonen et al., 2002) showed little impact on CA1 place fields in a familiar environment. Thus septal input is not necessary in the normal retrieval of a stored representation of the familiar environment. Conversely, MS activation caused a decrease in the ability to retrieve and/or stabilize the correct hippocampal representation of the environment.

\section{Effects of MS activation in a novel configuration}

In the novel configuration, increased septal activity disrupted the formation of stable place fields (i.e., fields emerged or stabilized slower) in young rats, whereas it accelerated this process in aged rats. Moreover, the way the environment was experienced during the first exposure affected how the same environment was represented $24 \mathrm{~h}$ later. Young rats that received carbachol during their initial experience in the novel configuration still had low place field reliability on their second exposure. In contrast, the reliability of place fields during the second novel configuration exposure was higher for carbachol-treated aged rats than for controls.

\section{Implications of the findings on models of memory encoding and retrieval}

CA1 neurons receive inputs from $\mathrm{EC}$ and $\mathrm{CA} 3$, both of which are modulated by the MS (Nakazawa et al., 2004). CA3 also receives input from the dentate gyrus, postulated to function as a pattern separator, allowing for the storage of multiple orthogonal representations within CA3 (McClelland and Goddard, 1996). Place fields in CA3 seem less affected by small modifications of the environment than in CA1 (Fyhn et al., 2002; Guzowski et al., 2004; Vazdarjanova and Guzowski, 2004), indicating that CA1 does not always directly reflect CA3 activity. The convergence of direct neocortical (EC) input with previously stored information (CA3) onto CA1 neurons allows CA1 to perform a comparison of a stored representation with the current environment (Fyhn et al., 2002). Place fields are constant in a familiar stable environment. However, no environment is completely stable; there are continuous fluctuations in auditory, visual, and olfactory stimuli. Under some conditions, these minor variations in neocortical input are ignored and a previously stored CA3 representation is activated. Interestingly, even major sensory changes such as turning off the lights (Markus et al., 1994) or changing the reward (Tabuchi et al., 2003) can have little effect on the location of place fields. Consequently, the degree of mismatch between EC and the stored CA3 representation cannot be the only factor for inducing encoding in CA1. Theta rhythm was proposed to be a signal for encoding (Hasselmo et al., 2002). Our results support this hypothesis, because carbachol-induced theta caused remapping even in a stable familiar environment. Normally, in a familiar environment, CA1 cells reflect the previously stored CA3 input and ignore minor sensory mismatches. Increasing the degree of mismatch by moderately modifying the environment (i.e., our novel configuration) and/or increasing septal activity in a familiar environment results in CA1 reflecting extrahippocampal input more than the previously stored CA3 input (Fig. 11A).

Septal modulation of the hippocampus is reduced during aging. In aged rats, the MS contains less cholinergic and GABAergic 


\section{A. Familiar environment}

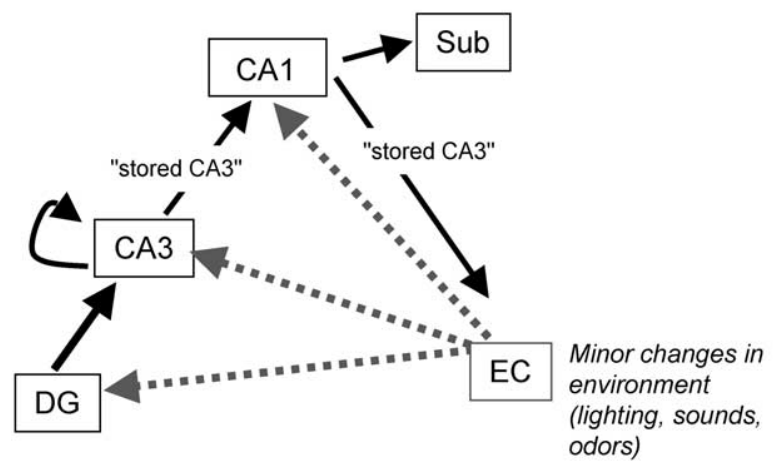

B.

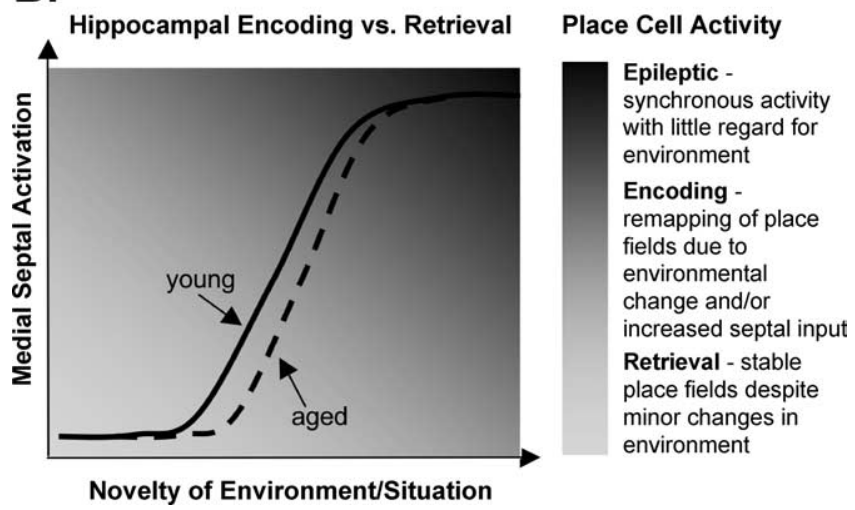

Figure 11. Models of encoding/retrieval in the hippocampus. $A$, Schematic of hippocampal connectivity and activity in a familiar environment. Neocortical input reaches the dentate (DG), $C A 3$, and CA1 through the EC. Despite minor changes in the environment (dashed arrows), the stored representation of the environment is retrieved and expressed in CA1. B, The effect of environmental novelty and/or MS activation on hippocampal place cell activity. Both novelty and septal activation can cause a transition from the hippocampus retrieving a stored representation to encoding a new representation of the environment. The hippocampus in aged animals is less responsive to changes in the environment; however, this can be countered through septal activation.

cells (Krzywkowski et al., 1995), and the septo-hippocampal projections are reduced (Gill and Gallagher, 1998; Potier et al., 2006). Although overall hippocampal theta power seems to be preserved (Shen et al., 1997), theta frequency potentiation declines in impaired aged rats (Tombaugh et al., 2002), and long-term potentiation (LTP) is harder to induce and decays more rapidly (Foster, 1999). Buzsaki (1989) proposed a two-stage model of memory encoding: during theta, information about the current environment reaches the hippocampus via the EC; during sharp waves, population bursts in CA3 may lead to LTP induction in CA1. Therefore, both theta and sharp wave/ripples are important for memory encoding. The predominance of theta and sharp wave/ ripple states may be altered in aged rats, such that the relative time the rat is in a theta state diminishes with aging. A carbacholinduced prolonged theta state (and consequent reduced occurrence of sharp wave/ripples) would benefit the aged rats by facilitating encoding in a new environment. In young rats with preserved theta states, the reduction in sharp wave/ripple state by carbachol would impair pattern completion in CA3 and manifest as reduced spatial information content and decreased reliability of place fields. Our results suggest that the decreased response of place fields to environmental manipulations in aging reflects a deficit in the transition of the hippocampus from retrieval to an encoding state because of a decline in MS modulation (Fig. $11 B$ ).
The use of cholinergic system enhancers in aged humans and rats has given conflicting results. Our data suggest the reason for the mixed behavioral results. Recall of previously well learned information does not require MS activation, and artificially activating this system will disrupt normal recall. Conversely, encoding of new information depends on an intact septo-hippocampal system, and the age-related impairments can be reversed by MS activation.

\section{References}

Alreja M, Wu M, Liu W, Atkins JB, Leranth C, Shanabrough M (2000) Muscarinic tone sustains impulse flow in the septohippocampal GABA but not cholinergic pathway: implications for learning and memory. J Neurosci 20:8103-8110.

Barnes CA, McNaughton BL (1980) Physiological compensation for loss of afferent synapses in rat hippocampal granule cells during senescence. J Physiol (Lond) 309:473-485.

Barnes CA, Suster MS, Shen J, McNaughton BL (1997) Multistability of cognitive maps in the hippocampus of aged rats. Nature 388:272-275.

Bartus RT, Dean III RL, Beer B, Lippa AS (1982) The cholinergic hypothesis of geriatric memory dysfunction. Science 217:408-414.

Bland BH (1986) The physiology and pharmacology of hippocampal formation theta rhythms. Prog Neurobiol 26:1-54.

Bunce JG, Sabolek HR, Chrobak JJ (2003) Intraseptal infusion of oxotremorine impairs memory in a delayed-non-match-to-sample radial maze task. Neuroscience 121:259-267.

Bunce JG, Sabolek HR, Chrobak JJ (2004a) Intraseptal infusion of the cholinergic agonist carbachol impairs delayed-non-match-to-sample radial arm maze performance in the rat. Hippocampus 14:450-459.

Bunce JG, Sabolek HR, Chrobak JJ (2004b) Timing of administration mediates the memory effects of intraseptal carbachol infusion. Neuroscience 127:593-600.

Buzsaki G (1989) Two-stage model of memory trace formation: a role for "noisy" brain states. Neuroscience 31:551-570.

Buzsaki G (2002) Theta oscillations in the hippocampus. Neuron 33:325-340.

Buzsaki G, Leung LW, Vanderwolf CH (1983) Cellular bases of hippocampal EEG in the behaving rat. Brain Res 287:139-171.

Chrobak JJ, Buzsaki G (1996) High-frequency oscillations in the output networks of the hippocamal-entorhinal axis of the freely behaving rat. J Neurosci 16:3056-3066.

Cressant A, Muller RU, Poucet B (2002) Remapping of place cell firing patterns after maze rotations. Exp Brain Res 143:470-479.

Csicsvari J, Hirase H, Czurkó A, Mamiya A, Buzsáki G (1999) Oscillatory coupling of hippocampal pyramidal cells and interneurons in the behaving rat. J Neurosci 19:274-287.

Foster TC (1999) Involvement of hippocampal synaptic plasticity in agerelated memory decline. Brain Res Brain Res Rev 30:236-249.

Frank LM, Stanley GB, Brown EN (2004) Hippocampal plasticity across multiple days of exposure to novel environments. J Neurosci 24:7681-7689.

Frank LM, Stanley GB, Brown EN (2006) Hippocampal and cortical place cell plasticity: implications for episodic memory. Hippocampus 16:775-784.

Frick KM, Gorman LK, Markowska AL (1996) Oxotremorine infusions into the medial septal area of middle-aged rats. Behav Brain Res 80:99-109.

Fyhn M, Molden S, Hollup S, Moser MB, Moser EI (2002) Hippocampal neurons responding to first-time dislocation of a target object. Neuron 35:555-566.

Gill TM, Gallagher M (1998) Evaluation of muscarinic m2 receptor sites in basal forebrain and brainstem cholinergic systems of behaviorally characterized young and aged Long-Evans rats. Neurobiol Aging 19:217-225.

Givens BS, Olton DS (1990) Cholinergic and GABAergic modulation of medial septal area, effect on working memory. Behav Neurosci 104:849-855.

Givens BS, Olton DS (1995) Bidirectional modulation of scopolamineinduced working memory impairments by muscarinic activation of the medial septal area. Neurobiol Learn Mem 63:269-276.

Guzowski JF, Knierim JJ, Moser EI (2004) Ensemble dynamics of hippocampal regions CA3 and CA1. Neuron 44:581-584.

Hasselmo ME, Hay J, Ilyn M, Gorchetchnikov A (2002) Neuromodulation, theta rhythm and rat spatial navigation. Neural Netw 15:689-707. 
Ikonen S, McMahan R, Gallagher M, Eichenbaum H, Tanila H (2002) Cholinergic system regulation of spatial representation by the hippocampus. Hippocampus 12:286-397.

Jenkins L, Myerson J, Joerding JA, Hale S (2000) Converging evidence that visuospatial cognition is more age-sensitive than verbal cognition. Psych Aging 15:157-175.

Judge SJ, Hasselmo ME (2004) Theta rhythmic stimulation of stratum lacunosum-moleculare in rat hippocampus contributes to associative LTP at a phase offset in stratum radiatum. J Neurophysiol 92:1615-1624.

Krzywkowski P, De Bilbao F, Senut MC, Lamour L (1995) Age-related changes in parvalbumin- and GABA-immunoreactive cells in the rat septum. Neurobiol Aging 16:29-40.

Lee MG, Chrobak JJ, Sik A, Wiley RG, Buzsaki G (1994) Hippocampal theta activity following selective lesion of the septal cholinergic system. Neuroscience 62:1033-1047.

Leutgeb S, Mizumori SJ (1999) Excitotoxic septal lesions result in spatial memory deficits and altered flexibility of hippocampal single-unit representations. J Neurosci 19:6661-6672.

Markowska AL, Olton DS, Givens BL (1995) Cholinergic manipulations in the medial septal area: age-related effects on working memory and hippocampal electrophysiology. J Neurosci 15:2063-2073.

Markus EJ, Barnes CA, McNaughton BL, Gladden V, Skaggs WE (1994) Spatial information content and reliability of hippocampal CA1 neurons. Effects of visual input. Hippocampus 4:410-421.

Markus EJ, Qin YL, Leonard B, Skaggs WE, McNaughton BL, Barnes CA (1995) Interactions between location and task affect the spatial and directional firing of hippocampus neurons. J Neurosci 15:7079-7094.

McClelland JL, Goddard NH (1996) Considerations arising from a complementary learning systems perspective on hippocampus and neocortex. Hippocampus 6:654-665.

McNaughton BL, Morris RG (1987) Chlordiazepoxide, an anxiolytic benzodiazepine, impairs place navigation in rats. Behav Brain Res 24:39-46.

Mizumori SJ, McNaughton BL, Barnes CA (1989) Reversible inactivation of the medial septum, selective effects on the spontaneous unit activity of different hippocampal cell types. Brain Res 500:99-106.

Nakazawa K, McHugh TJ, Wilson MA, Tonegawa S (2004) NMDA receptors, place cells and hippocampal spatial memory. Nat Rev Neurosci 5:361-372.

O'Keefe JO, Nadel L (1978) The hippocampus as a cognitive map. Oxford: Clarendon.

O’Keefe JO, Reece ML (1993) Phase relationship between hippocampal place units and the EEG theta rhythm. Hippocampus 3:317-330.

O'Keefe JO, Speakman A (1987) Single unit activity in the rat hippocampus during a spatial memory task. Exp Brain Res 68:1-27.

Oler JA, Markus EJ (2000) Age-related deficits in the ability to encode contextual change: a place cell analysis. Hippocampus 10:338-350.

Paxinos G, Watson C (1998) The rat brain in stereotaxic coordinates. San Diego: Academic.

Potier B, Jouvenceau A, Epelbaum J, Dutar P (2006) Age-related alterations of GABAergic input to CA1 pyramidal neurons and its control by nicotinic acetylcholine receptors in rat hippocampus. Neuroscience 142:187-201.

Rapp PR, Amaral DG (1991) Recognition memory deficits in a subpopulation of aged monkeys resemble the effects of medial temporal lobe damage. Neurobiol Aging 12:481-486.
Sabolek HR, Bunce JG, Chrobak JJ (2004a) Intraseptal tacrine can enhance memory in cognitively impaired young rats. NeuroReport 15:181-183.

Sabolek HR, Bunce JG, Chrobak JJ (2004b) Intraseptal cholinomimetic modulation of hippocampal synchronization in the freely-behaving rat: from theta to epileptiform activity. Soc Neurosci Abstr 30:897.5.

Shen J, Barnes CA, McNaughton BL, Skaggs WE, Weaver KL (1997) The effect of aging on experience-dependent plasticity of hippocampal place cells. J Neurosci 17:6769-6782.

Skaggs WE, McNaughton BL (1998) Spatial firing properties of hippocampal CA1 populations in an environment containing two visually identical regions. J Neurosci 18:8455-8466.

Skaggs WE, McNaughton BL, Wilson MA, Barnes CA (1996) Theta phase precession in hippocampal neuronal populations and the compression of temporal sequences. Hippocampus 6:149-172.

Smith TD, Adams MM, Gallagher M, Morrison JH, Rapp PR (2000) Circuit-specific alterations in hippocampal synaptophysin immunoreactivity predict spatial learning impairment in aged rats. J Neurosci 20:6587-6593.

Stewart M, Fox SE (1990) Do septal neurons pace the hippocampal theta rhythm? Trends Neurosci 13:163-168.

Tabuchi E, Mulder AB, Wiener SI (2003) Reward value invariant place responses and reward site associated activity in hippocampal neurons of behaving rats. Hippocampus 13:117-132.

Tanila H, Sipilä P, Shapiro M, Eichenbaum H (1997) Brain aging: impaired coding of novel environmental cues. J Neurosci 17:5167-5174.

Thompson LT, Best PJ (1990) Long-term stability of the place-field activity of single units recorded from the dorsal hippocampus of freely behaving rats. Brain Res 509:299-308.

Tombaugh GC, Rowe WB, Chow AR, Michael TH, Rose GM (2002) Thetafrequency synaptic potentiation in cal in vitro distinguishes cognitively impaired from unimpaired aged fischer 344 rats. J Neurosci 22:9932-9940.

Vazdarjanova A, Guzowski JF (2004) Differences in hippocampal neuronal population responses to modifications of an environmental context, evidence for distinct, yet complementary, functions of CA3 and CA1 ensembles. J Neurosci 24:6489-6496.

Wilson IA, Ikonen S, Gureviciene I, McMahan RW, Gallagher M, Eichenbaum H, Tanila H (2004) Cognitive aging and the hippocampus: how old rats represent new environments. J Neurosci 24:3870-3878.

Wilson IA, Ikonen S, Gallagher M, Eichenbaum H, Tanila H (2005) Ageassociated alterations of hippocampal place cells are subregion specific. J Neurosci 25:6877-6886.

Wilson MA, McNaughton BL (1993) Dynamics of the hippocampal ensemble code for space. Science 261:1055-1058.

Wu M, Shanabrough M, Leranth C, Alreja M (2000) Cholinergic excitation of septohippocampal GABA but not cholinergic neurons: implications for learning and memory. J Neurosci 20:3900-3908.

Wu M, Hajszan T, Leranth C, Alreja M (2003) Nicotine recruits a local glutamatergic circuit to excite septohippocampal GABAergic neurons. Eur J Neurosci 18:1155-1168.

Zhang HY, Watson ML, Gallagher M, Nicolle MM (2007) Muscarinic receptor-mediated GTP-Eu binding in the hippocampus and prefrontal cortex is correlated with spatial memory impairment in aged rats. Neurobiol Aging 28:619-626. 